\title{
EDITORIAL
}

\section{Making the Case for a New National Data Collection Effort on Physicians and Their Practices}

\author{
Catherine M. DesRoches, DrPH', Herbert S. Wong, $P h D^{2}$, Eugene C. Rich, $M D^{\prime}$, and Sumit R. \\ Majumdar, MD, $\mathrm{MPH}^{3}$ \\ ${ }^{7}$ Mathematica Policy Research, Cambridge, MA, USA; ${ }^{2}$ Agency for Healthcare Research and Quality, Rockville, MD, USA; ${ }^{3}$ Department of \\ Medicine, University of Alberta, Edmonton, AB, Canada.
}

KEY WORDS: survey research; health policy; physician workforce.

J Gen Intern Med 30(Suppl 3):S553-4

DOI: $10.1007 / \mathrm{s} 11606-015-3386-3$

(C) Society of General Internal Medicine 2015

$\mathrm{P}$ hysicians play a key role in the American health care system. Beyond providing direct medical care, they authorize the great majority of medical services, thus making them directly or indirectly responsible for access, quality, and a significant portion of U.S. health care spending. ${ }^{1}$ Accurate and timely information on physicians and the organizations in which they practice is essential to understanding the functioning of the U.S. health care system; further, the data so generated is likely to inform many other health care systems and hopefully lead to more generalizable methodological advances. As discussed in the papers in this supplement, physicians and their practice organizations are integral to the payment and delivery system reforms currently underway; evaluating success (or lack thereof) requires understanding diverse medical practices and how physicians and their organizations are responding to these policies.

Numerous data collection efforts focused on physicians and their practice organizations have been developed. These include large federally funded efforts such as the National Ambulatory Medical Care Survey and the Physician Component of the Medical Expenditures Panel Survey, as well as surveys conducted through research grants, foundations and other private organizations. However, these efforts are generally driven by the information needs of the research team, and they do not provide the comprehensive picture of physicians and organizations that can inform the broad policy community. Further, rapid changes in the way in which physicians work, as well as how their practices are organized, may require the development of novel survey items and methodologies. How this data collection should be structured and what its focus

$\overline{\text { The findings and conclusions in this article are those of the authors and do }}$ not necessarily represent the views of the Agency for Healthcare Research and Quality or the U.S. Department of Health and Human Services.

Published online June 24, 2015 should be is the overriding topic of the current supplement to the Journal of General Internal Medicine.

We believe that the pace of change in the U.S. health care system and the integral role played by physicians indicate a clear need for an ongoing, regular physician survey. Given the changes occurring at all levels of the health care market, we suggest that the survey be designed to achieve the following:

- Monitor over time the characteristics of all physicians in all specialties and the clinical, organizational, and financial contexts in which they operate, and

- Provide a database of these characteristics that can serve the analytical needs of the policy, research, and practice communities.

What should this new data collection effort look like? This is not an easy question to answer, and in the following papers, we focus on the groundwork that has already been laid and the challenges that need be overcome in developing a new survey including (but not limited to) the changing nature and economics of physician organizations, ${ }^{1,2}$ measurement issues related to primary care ${ }^{3,4}$ and to practice variations, ${ }^{5}$ and issues related to physician sampling. ${ }^{6}$

The organization of medicine continues to move away from one and two physician practices to more complicated arrangements, including large single and multi-specialty groups, hospital and health system ownership, and contracting arrangements. The complexity of these new organizations make it difficult to understand the true costs related to the provision of health care. In Fleming et al., the authors discuss the increasingly complicated inputs and outputs that should be assessed in order to measure costs, and how these have changed since the era of the solo physician. ${ }^{2}$ The authors also provide recommendations for how this work must be adapted to these new realities.

Among these realities are recent major policy changes that are focused on enhancing the provision of primary care. Underlying this focus is the belief that high quality, patientcentered, comprehensive primary care will result in lower costs and improved outcomes. Yet current metrics for understanding the scope of primary care provided in the physician office fall short, particularly in the area of comprehensiveness. Two papers by O'Malley et al. address these issues and offer recommendations and research priorities aimed toward 
supporting future measurement and understanding of the role of primary care features in health care costs and quality.,

There is also ample evidence that many clinical decisions made by physicians are inconsistent with current "best practices," resulting in under-use of highly effective services and overuse of wholly ineffective or marginal value services. The paper by Reschovsky, Rich, and Lake notes the multitude of factors shown to influence physician decisions, including characteristics of patients, practice sites, physician organizations, and local markets, as well as the individual characteristics of physicians themselves. ${ }^{1}$ This paper identifies the challenges and opportunities for health services and policy researchers to collect the information needed to better understand how polices may interact through this complex environment.

Finally, papers by DesRoches et al. ${ }^{5}$ and Converse et al. ${ }^{6}$ address important methodological issues related to surveying physicians and their practices. DesRoches et al. focus on the well-known shortcomings of databases used to construct samples of physicians for surveys. The authors offer empirical evidence of the accuracy of three physician databases and provide recommendations for further survey work. The paper by Converse et al. examines the issue of linking physician survey data to measures of point-of-care clinical decisions. The ability to make these linkages will substantially increase the value of future data collection through expanding the possible research questions that could be addressed.

The rapidly changing U.S. health care system presents significant challenges to conducting physician surveys. The growing complexity of physician organizations, the changing nature of the workforce, including demographic shifts and the growing role of non-physician clinicians, and the rapid pace with which health care reform and other private initiatives are being implemented all suggest the need for new efforts to track how physicians are responding to the changing environment. Toward that end, we are recommending a new ongoing data collection effort that is inclusive of all physicians in all specialties and practice arrangements. Efforts to comprehensively understand the success or failure of recent and future health care reform efforts will be substantially enhanced by the availability of such data. The papers published in this supplement to the Journal of General Internal Medicine begin to lay the groundwork for how such an effort should be structured.

Conflict of Interest: The authors have no relevant conflicts of interest to report.

Corresponding Author: Catherine M. DesRoches, DrPH; Mathematica Policy Research, 955 Massachusetts Avenue, Suite 801, Cambridge, MA 02139, USA (e-mail: cdesroches@mathematicmpr.com).

\section{REFERENCES}

1. Reschovsky J, Rich E, Lake T. Factors contributing to variations in physicians use of evidence at the point of care, a conceptual model. JGIM. doi:10.1007/s11606-015-3366-7.

2. Fleming C, Rich E, DesRoches C, Reschovsky J, Kogan R. Measuring changes in the economics of medical practice. JGIM. doi:10.1007/s11606015-3368-5.

3. O'Malley AS, Rich EC. Measuring comprehensive of primary care: challenges and opportunities. JGIM. doi:10.1007/s11606-015-3300-z.

4. O'Malley AS, Rich EC, Maccarone A, DesRoches CM, Reid R. Disentangling the linkage of primary care features to patient outcomes: a review of current literature, data sources, and measurement needs. JGIM. doi:10.1007/s11606-015-3311-9.

5. DesRoches CM, Barrett K, Harvey B, et al. The results are only as good as the sample. JGIM. doi:10.1007/s11606-015-3380-9.

6. Converse L, Carrier E, Barrett K, Rich EC, Reschovsky J. Methods of observing variations in physicians' decisions: the opportunities of clinical vignettes. JGIM. doi:10.1007/s11606-015-3365-8. 